\title{
PARENTING STRESS DENGAN KEKERASAN VERBAL PADA ANAK USIA SEKOLAH DI MASA PANDEMI COVID-19
}

\author{
Laeli Maghfiroh $^{1)}$, Fiki Wijayanti' ${ }^{2)}$ \\ 1,2Universitas Ngudi Waluyo \\ e-mail : lely.mgh@gmail.com
}

\begin{abstract}
ABSTRAK
Dampak pandemi COVID-19 di dunia pendidikan yaitu adanya kebijakan belajar dari rumah atau daring. Kondisi ini menjadi salah satu faktor pemicu parenting stress selama pandemi COVID-19. Orangtua yang tidak dapat mengelola parenting stress cenderung melakukan kekerasan verbal pada anak. Tujuan penelitian untuk mengetahui hubungan antara parenting stress dengan kekerasan verbal pada anak usia sekolah. Desain penelitian deskriptif korelasional dengan pendekatan cross sectional. Populasi dalam penelitian adalah anak kelas 4, 5 dan 6 sebanyak 102 anak. Teknik sampling penelitian ini menggunakan total sampling. Instrumen yang digunakan adalah lembar kuesioner parenting stress dan kekerasan verbal. Analisis data menggunakan uji kendall tau. Hasil penelitian menunjukkan bahwa parenting stress dalam kategori rendah 46,1\%, kategori sedang 43,1\%, dan kategori tinggi 10,8\%; kekerasan verbal pada anak dalam kategori rendah 78,4\%, kategori sedang $18,6 \%$, dan kategori tinggi 3\%. Hasil uji statistik kendall tau didapatkan hasil $p$-value 0.001 artinya ada hubungan signifikan antara parenting stress dengan kekerasan verbal pada anak usia sekolah di masa pandemi COVID-19. Orangtua diharapkan mampu mengelola parenting stress sehingga meminimalkan kekerasan verbal.
\end{abstract}

Kata kunci : anak usia sekolah; kekerasan verbal; parenting stress

\section{ABSTRACT}

The impact of the COVID-19 pandemic for education is the existence of a policy of study from home or online study. This condition is one of the factors that trigger parenting stress during the COVID-19 pandemic. Parents who cannot manage parenting stress tend to verbally abuse their children. The study aimed to identify the correlations between parenting stress and verbal abuse in school-age children. The study used descriptive correlational design with cross sectional approach. The population were 102 children in grades 4, 5, and 6. The sample were selected with total sampling technique. The data were collected with parenting stress and verbal abuse questionnaire. The data analysis used Kendall Tau Test. The results showed that parenting stress in the low category 46,1\%, medium category 43,1\%, and high category 10,8\%; verbal violence against children was in the low category 78,4\%, the medium category 18,6\%, and the high category 3\%. The results of the Kendall Tau Test showed a p-value 0.001 meaning that there was a significant relationship between parenting stress and verbal abuse in school-age children during the COVID-19 pandemic. Parents are expected to be able to manage parenting stress to minimize verbal violence.

Keyword : school-age children; verbal abuse; parenting stress

\section{PENDAHULUAN}

COVID-19 saat ini masih ada di Indonesia dan penyebaran penyakit tersebut sangat cepat. Bukan hanya di Indonesia saja, namun penjuru dunia sedang menghadapi krisis kesehatan. Salah satu kebijakan dari COVID-19 adalah adanya Pembatasan Sosial Berskala Besar (PSBB) (Kompas,
2020). Saat ini dampak dari wabah COVID-19 juga dirasakan oleh dunia Pendidikan yaitu dengan adanya Surat Edaran dari Mendikbud mengenai pembelajaran secara daring untuk mencegah penyebaran COVID-19 yang menyarankan siswa belajar dari rumah. Pembelajaran yang dilakukan secara daring dapat membuat orangtua 
memiliki tugas tambahan dalam bekerja, mengasuh dan mendampingi anaknya ketika pembelajaran jarak jauh. Hal tersebut dapat menjadi faktor pemicu stres pada orangtua.

Berdasarkan laporan The Hidden Impact of COVID-19 dari Save The Children 2020 yang dilansir dari Bloomberg Opinion (Schott, 2020) yang dilakukan dengan survei di 37 negara pada bulan Mei-Juli 2020 dengan melibatkan 17.565 orang tua dan pengasuh serta 8.069 anak. Hasil survei menunjukkan persentase stres orangtua selama pandemi COVID-19 sebanyak $83,3 \%$ pada 4 minggu pertama dan sebanyak $95,1 \%$ pada 4 minggu terakhir. Selain itu sepertiga rumah tangga yang memiliki seorang anak dan pengasuh melaporkan kekerasan di rumah, serta anak-anak melaporkan bahwa kekerasan meningkat saat sekolah daring dibandingkan saat sekolah tatap muka.

Stres dapat dialami oleh setiap individu dalam kehidupan sehari-hari. Akan tetapi stres dalam mengasuh anak atau parenting stress memiliki kekhasan tersendiri. Parenting stress merupakan pengalaman dan atau ketidaknyamanan dalam mengasuh yang dialami orangtua dari tuntutan terkait dengan peran sebagai orangtua (Hayes \& Watson, 2013). Parenting stress merupakan respon psikologis yang timbul pada orangtua yang terlibat dalam proses pengasuhan anak, atau ketika orangtua tidak bisa memenuhi tuntutan sebagai orangtua yang sesuai harapan baik dari diri sendiri maupun orang lain (Holly et al., 2019).

Tanpa disadari, orangtua pernah melakukan kekerasan pada anak. Salah satu bentuk kekerasan tersebut ialah kekerasan verbal (verbal abuse) yang merupakan kekerasan terhadap perasaan dengan menyampaikan atau mengungkapkan kata-kata yang kasar misalnya memarahi, membentak, menghina dan memaki. Kekerasan verbal merupakan tindakan lisan yang dapat menimbulkan konsekuensi emosional yang berdampak psikis bagi anak (S. P. Lestari et al., 2018).

Hasil survei yang dilakukan oleh Wahana Visi Indonesia (WVI, 2020) tentang ringkasan penilaian cepat COVID-19 dan anak-anak di Indonesia, sebanyak $61,5 \%$ anak-anak mengalami kekerasan verbal di masa pandemi. Ada lima bentuk kekerasan verbal diantaranya: 1) Tidak sayang dan dingin kepada anak, 2) Intimidasi anak, 3) Mengecilkan dan mempermalukan anak, 4) Kebiasaan perilaku mencela anak, 5) Tidak mengindahkan dan atau menolak anak (T. Lestari, 2016)

Menurut Centers for Disease Control and Prevention (CDC, 2020) salah satu faktor resiko yang mempengaruhi terjadinya kekerasaan pada anak yang dilakukan oleh orangtua adalah parenting stress. Beberapa studi menunjukkan bahwa ada hubungan antara parenting stress dengan potensi untuk penganiayaan anak dan variasi yang ekstrim dalam tingkah laku parenting yang maladaptif (Ahern, 2004).

Studi (Brown et al., 2020) orangtua yang mengalami parenting stress seringkali menempatkan anak pada resiko kekerasan dan pengabaikan anak. Menurut Keong et al. (2020) bahwa parenting stress yang tinggi dikaitkan dengan pengasuhan yang buruk seperti mengasuh dengan kasar dan hubungan orangtua-anak menjadi buruk, sehingga orangtua menjadi otoriter, kasar dan kurang responsif dalam mengasuh anak.

Wawancara sederhana terhadap lima orangtua, didapatkan hampir semua pernah berteriak, memarahi serta membentak. Tiga responden tidak mengetahui bahwa memarahi, berteriak, membentak merupakan salah satu tindak kekerasan verbal. Sedangkan dua responden mengetahui bahwa memarahi, berteriak dan membentak merupakan kekerasan verbal.

Berdasarkan uraian diatas, peneliti merasa tertarik untuk meneliti "Parenting Stress dengan Kekerasan 
Verbal pada Anak Usia Sekolah di Masa Pandemi COVID-19". Tujuan penelitian ini adalah untuk mengetahui hubungan antara parenting stress dengan kekerasan verbal pada anak usia sekolah di masa pandemi COVID19.

\section{METODE PENELITIAN}

Jenis penelitian ini menggunakan deskriptif korelasional dengan pendekatan cross sectional. Penelitian dilaksanakan pada 27-30 Januari 2021 di SDN Wringinputih 02. Sampel penelitian adalah seluruh anak kelas 4 , 5, dan 6 berjumlah 102 anak. Teknik sampel dengan menggunakan total sampling.

Proses penelitian dilaksanakan dengan memberikan kuesioner parenting stress dan kekerasan verbal. Analisa data secara univariat untuk melihat gambaran distribusi frekuensi dan porposinya pada setiap variabel. Selanjutnya dilakukan analisa bivariat untuk melihat hubungan parenting stress dengan kekerasan verbal pada anak usia sekolah di masa pandemi COVID-19.

\section{HASIL DAN PEMBAHASAN}

a. Gambaran parenting stress yang dialami orangtua

Tabel 1. Distribusi Frekuensi Parenting Stress Orangtua

Berdasarkan tabel 1 menunjukkan bahwa parenting stress yang dialami orangtua paling banyak termasuk dalam kategori stres rendah dengan 47 responden $(46,1 \%)$.

Salah satu karakteristik yang mempengaruhi parenting stress yaitu jenis kelamin, usia orangtua, jumlah anak, pendidikan, pekerjaan penghasilan perbulan. Menurut Hansson et al. (2013) menyebutkan bahwa pada usia dewasa madya dan dewasa akhir orangtua telah banyak menyerap informasi sehingga memiliki kematangan dan pengalaman dalam mengasuh anak dengan baik. Jika orangtua berusia muda akan relatif mengalami parenting stress dari usia dewasa madya atau akhir pada dalam mengasuh anak (Nuha et al., 2020).

Tingkat pendidikan orangtua dalam penelitian ini mayoritas tingkat pendidikan SMA (42.2\%). Sejalan dengan penelitian Muliana (2014) tingkat pendidikan orangtua berperan penting dalam menerapkan pola pengasuhan orangtua yang baik dan menyenangkan terhadap anak.

Penelitian lain menyatakan orangtua yang kurang membaca dan kurang mencari informasi akan memiliki pengetahuan yang kurang daripada orangtua yang sering membaca dan rajin mencari informasi maka pengetahuannya lebih baik (Jeniu et al., 2017). Hal ini dapat menyebabkan ada tidaknya parenting stress antara orangtua berpendidikan rendah dan tinggi. Selain itu, pendidikan dan pengalaman orangtua akan mempengaruhi persiapan orangtua dalam menjalankan proses pengasuhan.

Pendapatan keluarga seringkali dikaitkan dengan status kemapanan ekonomi suatu keluarga. Masalah keuangan seringkali mendorong timbulnya parenting stress. Aspek keuangan dapat berupa tingkat penghasilan orangtua yang rendah dan dihadapkan pada tuntutan kebutuhan yang tinggi, sehingga status ekonomi sangat berpengaruh pada hubungan

\begin{tabular}{lcc}
\hline $\begin{array}{c}\text { Parenting } \\
\text { Stress }\end{array}$ & (f) & $(\boldsymbol{\%})$ \\
\hline Rendah & 47 & 46,1 \\
Sedang & 44 & 43,1 \\
Tinggi & 11 & 10,8 \\
Total & 102 & 100,0 \\
\hline orangtua dengan anak (Lestari, 2018). \\
Faktor struktur & keluarga juga \\
mendorong adanya parenting stress \\
yang berupa jumlah anak yang banyak. \\
Semakin banyak anak yang diasuh, \\
semakin tinggi pula beban perawatan \\
dan kebutuhan yang diperlukan
\end{tabular}


orangtua, hal tersebut yang menimbulkan tekanan pada orangtua. Karena jumlah anak akan mempengaruhi peran orangtua dalam memenuhi kebutuhan anak, selain itu tekanan yang dialami orangtua bertambah (Lestari, 2018).

b. Gambaran kekerasan verbal yang dialami anak usia sekolah

Tabel 2. Distribusi Frekuensi Kekerasan Verbal Pada Anak Usia Sekolah

\begin{tabular}{ccc}
\hline $\begin{array}{c}\text { Kekerasan } \\
\text { Verbal }\end{array}$ & $(\mathbf{f})$ & $(\boldsymbol{\%})$ \\
\hline Rendah & 80 & 78.4 \\
Sedang & 19 & 18.6 \\
Tinggi & 3 & 3 \\
Total & 102 & 100.0 \\
\hline
\end{tabular}

Berdasarkan tabel 2 dapat diketahui bahwa kekerasan verbal pada anak usia sekolah mayoritas termasuk dalam kategori kekerasan verbal rendah sejumlah 80 responden $(78.4 \%)$.

Salah satu faktor kekerasan verbal pada anak yang dilakukan orangtua yaitu pengalaman masa kecil orangtua, jenis kelamin, usia orangtua, pendidikan, pekerjaan, dan penghasilan perbulan. Berdasarkan hasil penelitian (Armiyanti et al., 2017) diperoleh bahwa pengalaman verbal abuse oleh keluarga pada anak usia sekolah sering dilakukan oleh orang terdekat khususnya seorang ibu. Penelitian yang telah dilakukan di Kenya dengan ibu sebanyak 241 responden, menunjukkan hasil bahwa khususnya mereka yang masih berusia relatif muda cenderung menggunakan kekerasan verbal pada anak-anaknya ketika anak dianggap kurang kooperatif (Gunarsa, 2006).

Kekerasan verbal pada anak yang dilakukan orangtua disebabkan oleh beberapa hal, misalnya orangtua memiliki pengalaman kekerasan dimasa kecilnya akan menjadi pencetus terjadi kekerasan verbal pada anaknya (Lestari, 2016). Orangtua yang melakukan kekerasan verbal seperti membentak anak, dianggap sebagai hal wajar karena dampak kekerasan verbal tidak terlalu berat dibandingan kekerasan fisik.

Sejalan dengan penelitian yang dilakukan Fitriana et al. (2015) bahwa pengalaman orangtua dimasa kecilnya memiliki pengaruh terhadap perilaku kekerasan verbal pada anak. Orangtua yang tidak memiliki pengalaman kekerasan dimasa kecilnya dan memiliki pengalaman pola asuh yang baik cenderung melakukan hal yang sama terhadap anaknya.

Faktor yang mempengaruhi orangtua melakukan kekerasan verbal adalah faktor ekonomi yang dipicu kemiskinan dan tekanan pekerjaan orangtua (Lestari, 2016). Selaras dengan penelitian yang dilakukan oleh Kuspartianingsih (2012) menunjukkan kemiskinan cenderung menimbulkan stres, rasa ketidakberdayaan serta kekecewaan dalam mengatasi status ekonomi yang menjadikan orangtua mudah melampiaskan amarah orangtua kepada anak. Namun terdapat perbedaan pada penelitian oleh Fitriana et al. (2015) bahwa penghasilan orangtua tidak berhubungan dengan perilaku tindak kekerasan verbal pada anak.

Salah satu karakteristik orangtua yang melakukan kekerasan verbal pada anaknya yaitu orangtua yang memiliki pendidikan rendah. Penelitian oleh Indika dan Rokhnawati (2017) menyatakan bahwa pengetahuan merupakan salah satu faktor yang mempengaruhi perilaku kekerasan verbal pada anak. Berdasarkan penelitian lain (Herlina \& Purwati, 2016) terdapat hubungan tingkat pengetahuan dengan perilaku kekerasan verbal orangtua pada anak.

c. Hubungan antara parenting stress dengan kekerasan verbal pada anak usia sekolah di masa pandemi COVID19 
Tabel 3. Hubungan antara Parenting Stress dengan Kekerasan Verbal pada Anak Usia Sekolah di Masa Pandemi COVID - 19.

\begin{tabular}{|c|c|c|c|c|c|c|c|c|c|}
\hline \multirow{4}{*}{$\begin{array}{l}\text { Parenting } \\
\text { Stress }\end{array}$} & \multicolumn{8}{|c|}{ Kekerasan Verbal } & \multirow{3}{*}{$\begin{array}{c}p- \\
\text { value }\end{array}$} \\
\hline & \multirow{2}{*}{\multicolumn{2}{|c|}{$\begin{array}{c}\text { Kekerasan } \\
\text { Verbal Rendah }\end{array}$}} & \multirow{2}{*}{\multicolumn{2}{|c|}{$\begin{array}{c}\text { Kekerasan } \\
\text { Verbal Sedang }\end{array}$}} & \multirow{2}{*}{\multicolumn{2}{|c|}{$\begin{array}{c}\text { Kekerasan } \\
\text { Verbal Tingg }\end{array}$}} & \multicolumn{2}{|c|}{ Total } & \\
\hline & & & & & & & & & \\
\hline & $\mathbf{F}$ & $\%$ & $\mathbf{f}$ & $\%$ & $\mathbf{F}$ & $\%$ & $\mathbf{F}$ & $\%$ & \\
\hline Stres Rendah & 42 & 89.4 & 5 & 10.6 & 0 & 0.0 & 47 & 100 & 0.001 \\
\hline Stres Sedang & 36 & 81.4 & 8 & 18.2 & 0 & 0.0 & 44 & 100 & \\
\hline Stres Tinggi & 2 & 18.2 & 6 & 54.5 & 3 & 27.3 & 11 & 100 & \\
\hline Total & 80 & 78.4 & 19 & 18.9 & 3 & 2.9 & 102 & 100 & \\
\hline
\end{tabular}

Berdasarkan tabel 3 dapat diketahui bahwa terdapat hubungan signifikan parenting stress dengan kekerasan verbal anak ( $p$-value 0.001). Orangtua anak memiliki parenting stress termasuk kategori stres rendah dengan kekerasan verbal rendah 42 responden $(89.4 \%)$, stres sedang dengan kekerasan verbal sedang 8 responden $(18.2 \%)$, dan stres tinggi dengan kekerasan verbal tinggi 3 responden (27.3\%).

Stres rendah dengan kekerasan verbal sedang 5 responden (10.6\%), stres sedang dengan kekerasan verbal rendah 36 responden (81.4\%), stres tinggi dengan kekerasan verbal rendah 2 responden (18.2\%) dan stres tinggi dengan kekerasan verbal sedang 6 responden $(54.4 \%)$.

Orangtua yang memiliki anak usia sekolah berada pada tahapan perkembangan kritis dimana pengalaman sekolah anak dengan berbagai tuntutan tugas perkembangan dan tugas sekolah akan menjadi stressor bagi orangtua. Parenting stress merupakan suatu ketegangan dan tekanan yang membawa orangtua pada kondisi yang tidak menyenangkan dalam proses pengasuhan sehingga kesulitan beradaptasi dalam menjalankan tuntutan peran sebagai orangtua. Gunarsa (2006) mengatakan bahwa beban yang ditimbulkan dari parenting stress akan mengubah sikap orangtua dalam mengasuh anak berupa perilaku kasar dan mengabaikan anak.

Orangtua yang mengalami parenting stress dengan kategori stres rendah cenderung memiliki perilaku kekerasan verbal rendah. Hal ini dapat terjadi karena adanya perlakuan orangtua terhadap anak dengan baik sejak kecil. Hal tersebut sejalan dengan penelitian (Yuliawati, 2008) sebanyak $36,1 \%$ responden yang mengalami stres dengan memiliki perilaku kekerasan verbal terhadap anak, sehingga dapat disimpulkan bahwa adanya stress yang dialami oleh orangtua akan mempengaruhi kekerasan verbal terhadap anaknya.

Hal ini juga memungkinkan karena pendidikan orangtua yang cukup, menurut (Mysa \& Fithria, 2016) semakin tinggi tingkat pendidikan yang ditempuh orangtua maka akan semakin mudah orangtua menerima sebuah informasi yang didapat.

Adapun hasil penelitian yang menunjukkan responden yang memiliki stres sedang dengan kecenderungan kekerasan verbal sedang sebanyak $8 \quad(18.2 \%)$ serta responden yang memiliki stres tinggi dengan kecenderungan kekerasan verbal tinggi sebanyak 3 responden (27.3\%). Faktor yang menyebabkan kekerasan verbal meliputi pengetahuan orangtua, pengalaman orangtua, ekonomi, dan lingkungan (Lestari, 2016).

Hasil penelitian ini sejalan dengan penelitian Nugrahani (2015) menunjukkan hasil terdapat hubungan yang positif terkait parenting stress dengan kencenderungan perilaku kekerasan verbal terhadap anak. Penelitian lain (Ratnasari \& Kuntoro, 2017) juga menyatakan parenting stress memiliki hubungan dengan kekerasan verbal pada anak dalam rumah tangga. Mengasuh anak 
merupakan proses aktivitas yang penuh tekanan, diharapkan orangtua dapat mengatasi situasi penuh tekanan agar pola mengasuh anak lebih menyenangkan, dan hubungan interaksi orangtua dengan anak tidak merenggang (Lestari, 2018).

\section{KESIMPULAN}

Orangtua anak usia sekolah memiliki parenting stress mayoritas termasuk kategori stress rendah dengan kekerasan verbal rendah 42 responden (89.4\%). Kekerasan verbal pada anak usia sekolah mayoritas termasuk dalam kategori kekerasan verbal rendah sejumlah 80 responden $(78.4 \%)$. Terdapat hubungan signifikan parenting stress dengan kekerasan verbal anak ( $p$-value 0.001).

\section{SARAN}

Orangtua diharapkan mampu mengelola parenting stress sehingga meminimalkan terjadinya kekerasan verbal.

\section{REFERENSI}

Ahern, L. S. (2004). Psychometric Properties Of The Parenting Stress Index-Short Form. Releigh: Faculty of Psychology North Carolina State University.

Armiyanti, I., Aini, K. and, \& Rista, A. (2017). Pengalaman Verbal Abuse oleh Keluarga pada Anak Usia Sekolah di Kota Semarang. Jurnal Keperawatan Sodirman (The Soedieman ), 12(1), 1220.

Brown, S. M., Doom, J. R., Lechuga-Peña, S., Watamura, S. E., \& Koppels, T. (2020). Stress and parenting during the global COVID-19 pandemic. Child Abuse and Neglect, July. https://doi.org/10.1016/j.chiabu.2020. 104699

Centers for Disease Control and Prevention (CDC). (2020). Risks Protective Factors. Centers for Disease Control and Prevention (CDC). Retrieved from https://www.cdc.gov/violencepreventi on/childabuseandneglect/riskprotectiv efactors.html
Fitriana, Y., Pratiwi, K., \& Sutanto, A. V. (2015). Faktor-Faktor Yang Berhubungan Dengan Perilaku Orang Tua Dalam Melakukan Kekerasan Verbal Terhadap Anak Usia PrA. Jurnal Psikologi Undip, 14(1), 81-93.

Gunarsa, D. S. (2006). Bunga Rampai Psikologi Perkembangan: Dari Anak Sampai Usia Lanjut. BPK Gunung Mulia.

https://books.google.com/books/about/ Dari_anak_sampai_usia_lajut.html?hl $=\mathrm{id} \& \mathrm{id}=\mathrm{GUAGhG} 74 \mathrm{nH} 4 \mathrm{C}$

Hansson, P., Rounnlund, M., Juslin, P., \& Nilsson, L. (2013). Adult Age Differences in the Realism of Confidence Judgmens: Overconfidence. Psychology and Aging, 3(23), 531-544.

Hayes, S. A., \& Watson, S. L. (2013). The Impact of Parenting Stress: A Metaanalysis of Studies Comparing the Experience of Parenting Stress in Parents of Children With and Without Autism Spectrum Disorder. 629-642. https://doi.org/10.1007/s10803-0121604-y

Herlina, A., \& Purwati, Y. (2016). Hubungan Tingkat Pengetahuan Dengan Perilaku Verbal Abuse Orangtua Pada Anak Di Susun Kuwon Sidomulyo Bambanglipuro Bantul Yogyakarta.

Holly, L. E., Fenley, A. R., Kritikos, T. K., Merson, R. A., Abidin, R. R., \& Langer, D. A. (2019). Evidence-Base Update for Parenting Stress Measures in Clinical Samples. Journal of Clinical Child and Adolescent Psychology, 48(5), 685-705. https://doi.org/10.1080/15374416.201 9.1639515

Indika, L. M., \& Rokhnawati, D. (2017). Hubungan Pengetahuan Orangtua Dengan Perilaku Kekerasan Verbal Pada Anak di TK ABA Tegalrejo. http://digilib.unisayogya.ac.id//3045/1/ naskah\%25publikasi.Leony\%2520Ma nggivera\%252oIndika.1610104464.pd $\mathrm{f}$

Jeniu, E., Widodo, D., \& Widiani, E. (2017). Hubungan Pengetahuan Tentang Autisme Dengan Tingkat Kecemasan Orangtua Yang Memiliki 
Anak Autisme di Sekolah Luar Biasa Bhakti Luhur Malang. Jurnal Ilmiah Keperawatan: Nursing News, 2(2), 3242.

Keong, G. C. S., Lanier, P., \& Ju, P. W. Y. (2020). Mediating Effects of Parental Stress on Harsh Parenting And Parentchild Relationship During Coronavirus (Covid-19) Pandemic in Singapore. Journal of Family Violence, 1-38. https://osf.io/preprints/vnf4j/

Kompas. (2020). Bersiap tameng ekonomi untuk dampak corona. Kompas.Com. https://jeo.kompas.com/bersiaptameng-ekonomi-untuk-dampakwabah-corona

Kuspartianingsih, S. (2012). Hubungan antara Verbal Abuse Orang Tua dengan Perilaku Agresif pada Remaja Agresif di Sekolah Menengah Pertama Negeri 129 Jakarta Tahun 2012. 1.

Lestari, S. (2018). Psikologi Keluarga: Penanaman Nilai \& Penanganan Konflik dalam Keluarga (Cetak ke-5, p. 41). Prenadamedia Group.

Lestari, S. P., Royhanaty, I., \& Amah, E. S. L. (2018). Hubungan Perilaku Verbal Abuse Orang Tua Dengan Perilaku Bullying Pada Anak Usia Sekolah. Jurnal Ilmiah Permas: Jurnal Ilmiah STIKES Kendal, 8(1), 63-66.

Lestari, T. (2016). Verbal Abuse: Dampak Buruk dan Solusi Penanganannya pada Anak (Cetak Pert). Psikosain.

Muliana. (2014). Pengaruh Karakteristik Orang Tua Terhadap Jenis Pola Asuh dalam Merawat Anak Penyandang Autisme. FIK UI, 4.

Mysa, A. Y., \& Fithria. (2016). Pengetahuan Orang Tua Tentang Kekerasan Verbal Pada Anak Pra Sekolah Di AceH. 1-7.

Nugrahani, S. (2015). Hubungan Parenting Stress dengan Kecenderungan Perilaku Kekerasan Terhadap Anak.

Nuha, F. A., Putri, A. M., \& Triswanti, N. (2020). Hubungan antara karakteristik orang tua dengan stres pengasuhan pada orang tua anak gangguan spektrum autisme. Journal Psikologi Malahayati, 2(2), 36-47.

Rahmawati, I. N. (2006). Faktor-Faktor Yang Mempengaruhi Orang Tua Melakukan Verbal Abuse Pada

\section{Anaknya Di Kelurahan Bulusan Kecamatan Tembalang Kota Semarang.}

Ratnasari, K. A., \& Kuntoro. (2017). Hubungan Parenting Stress, Pengasuhan Dan Penyesuaian Dalam Keluarga Terhadap Perilaku Kekerasan Anak Dalam Rumah TanggA. Jurnal Manajemen Kesehatan, 3(1), 86-98.

Schott, B. (2020). Covid's Emotional Toll on the World's Youngsters. Bloomberg Opinion.

https://www.bloomberg.com/opinion/a rticles/2020-09-25/covid-s-emotionaltoll-on-the-world-s-youngsters

WVI. (2020). Ringkasan Penilaian Cepat COVID-19 dan Anak-Anak di Indonesia. Wahana Visi Indonesia.

Yuliawati, A. (2008). Hubungan Tingkat Stres Orangtua dengan Perilaku Kekerasan Verbal pada Anak di Kelurahan Jabungan Kecamatan Banyumanik Kota Semarang. Nursing Science Program, 76(3), 61-64. 